\title{
Prática docente frente às questões de gênero no cotidiano das aulas de educação física
}

\author{
Jairo Antônio da Paixão ${ }^{1}$ \\ Camila Quintão Ribeiro ${ }^{2}$
}

\begin{abstract}
Resumo
O estudo analisou a atuação de professores frente à categoria gênero nas aulas de Educação Física no ensino fundamental I e II, a partir de uma investigação de campo, descritiva e de cunho qualitativo, foram realizadas 40 sessões de observação sistemática de aulas e quatro entrevistas com quatro professores. Inferiu-se a prevalência de silenciamento das questões relacionadas a gênero na atuação indistinta de professoras e professores. Tal silenciamento se faz presente na forma de estruturação e condução das aulas, marcado pela ausência de equidade na participação de alunos e alunas nas atividades propostas nas aulas.
\end{abstract}

Palavras-chave: Gênero; Escola; Educação Física; Ensino fundamental.

\section{Teaching practice and gender issues in the daily education of physical educaction Title in English}

\section{Abstract}

The study analyzed the performance of teachers facing the gender category in Physical Education classes in elementary education, based on a descriptive and qualitative field research, 40 sessions of systematic observation of classes and four interviews with four teachers. The prevalence of silencing of issues related to gender in the indistinct performance of teachers and teachers was inferred. Such silencing is present in the form of structuring and conducting classes, the predominance of sexism, marked by the lack of equity in the participation of students in the activities proposed in class.

Keywords: Gender; School; Physical Education; Elementary education.

\section{Introdução}

Inexoravelmente, vive-se numa sociedade marcada por diferentes formas de exclusões, dentre as quais se destaca a questão de gênero, entendido como construção social das ideias sobre os papéis próprios aos homens e às mulheres nos mais diferentes grupamentos humanos (SILVA; GOMES; QUEIRÓS, 2006). Dito de outra forma é uma maneira de se referir às origens exclusivamente sociais das identidades subjetivas de homens e mulheres. Equivocadamente, tal construção estrutura-se a partir da diferença presente nas relações que se estabelecem entre o masculino e o feminino, em que não somente prevalece à figura do homem, como por sua vez,

\footnotetext{
${ }^{1}$ Universidade Federal de Viçosa, Viçosa, MG, jairopaixao@ufv.br

2 Universidade Federal de Viçosa, Viçosa, MG, cq.ribeiro@hotmail.com 
subjuga às mulheres a papeis secundários exercidos nos diferentes setores da sociedade (CRUZ; PALMEIRA, 2009).

Geralmente, a escola é apontada como uma instituição de grande influência na delimitação de identidades de gênero na sociedade. Tal entendimento se deve ao fato de se tratar de um espaço de formação e, por sua vez, por possibilitar manifestações nesse campo, haja vista que os alunos, enquanto sujeitos cognoscentes, imersos nos processos da educação formal identificam e expressam valores e ações da construção cultural humana, reproduzindoas e transformando-as. Com isso, ao longo do processo formativo, espera-se da escola propostas pedagógicas que propiciem o repensar dessas representações, com vistas à promoção da igualdade e autonomia entre gêneros e o respeito pelas diferenças (CORSINO; AUAD, 2012).

No entanto, sem considerar a vertente niilista, vê-se que a escola enquanto instituição nomeadamente social produz e reproduz valores e crenças vigentes na sociedade, e como tal, as questões de gênero nem sempre são abordadas de forma a superar possíveis desvios. Como bem reiteram Pereira e Mourão (2005), a escola em suas ações cotidianas separa e demarca o que é considerado socialmente pertencente ao mundo feminino e ao mundo masculino. Assim, a reprodução de modelos hegemônicos de gênero é naturalizada, sem que os atores envolvidos se deem conta disso no âmbito das práticas escolares, como por exemplo, na definição das cores dos materiais didáticos e equipamentos, nas brincadeiras na hora do recreio, ora definidas por estereótipos de gênero ligados à masculinidade, à feminilidade e à sexualidade (MIRANDA; MAIA, 2017).

Mais especificamente, no campo da Educação Física, que tem como objeto de estudo o corpo e o movimento, essas representações de gênero se destacam tanto nas diferenças das capacidades físicas entre os sexos, quanto por estereótipos criados pela sociedade e reproduzidos pelos alunos na ambiência da escola. Nesse sentido, Corsino e Auad (2012), afirmam que as relações de gênero nas aulas de Educação Física apresentam uma relação de hierarquização entre o masculino e o feminino, estabelecendo relações de poder tanto na organização quanto no modo de fazer.

Parece prevalecer uma espécie de pedagogia que educa de modo diferenciado os corpos de meninos e meninas, em que é possível identificar a construção de masculinidade em que os esportes coletivos, as brincadeiras de lutas, o suor, o esforço físico intenso, a competição e certa 
violência consentida são estimulados entre os meninos (LOURO, 2010). Já com relação às meninas, tem-se a produção de uma feminilidade em que sobressaem aspectos como obediência, delicadeza em que conteúdos como as ginásticas e o voleibol são empregados como ingredientes de uma educação que produz um determinado tipo de garota (MATTOS; JAEGER, 2015).

Com isso, no cotidiano das aulas de Educação Física, é esperado e aceito que os meninos ocupem as quadras esportivas e que as meninas brinquem ou fiquem sentadas em grupinhos conversando à margem do território dominado pelos meninos. Como resultante deste processo não é raro a recusa por parte das meninas em participar de atividades que envolvam esforço físico. Por outro lado, comumente, são os próprios meninos que rejeitam a participação das meninas, por acreditarem a participação delas nas aulas significam invasão de território pertencente exclusivamente a eles.

Geralmente, os professores de Educação Física justificam o emprego de práticas pedagógicas sexistas com base nos aspectos de natureza biológica como força, velocidade, maior engajamento e habilidade motora que, segundo eles, inviabilizam um trabalho equânime entre meninos e meninas no trato dos conteúdos nas aulas. Nesse rol de características historicamente utilizadas para justificar o sexíssimo nas aulas de Educação Física, como argumentam Uchoga e Altmann (2016), tem-se cristalizado a ideia de que no trato das diferentes práticas corporais trabalhadas no cotidiano das aulas, o destacar-se e a execução dos papéis decisivos nas jogadas, encontra-se focado ao gênero masculino. Embora essa percepção nem sempre se confirme, haja vista que uma parcela considerável de meninas também se destaca nas atividades e disputam relações de poder nas diversas práticas corporais, a crença de que eles, quando comparados a elas, são mais habilidosos, possuem mais força e velocidade, já interfere previamente nas formas de participar do jogo. Entretanto, mesmo que tais construções de gênero que colocam os meninos em vantagem não sejam verdades absolutas, muitas vezes, as meninas esquivam-se de certas modalidades esportes e outros conteúdos da Educação Física por não se sentir capazes.

Porém, é importante levar em consideração que o professor de Educação Física tem um eminente papel pedagógico na questão do gênero na escola, pois conforme afirma Kunz (2003), a Educação Física constitui uma área do saber, que pela sua especificidade, acentuam-se, as diferenças entre meninos e meninas e este espaço deve e pode ser explorado a fim de reeducar 
os alunos na busca de novas posturas e reflexões diante dos conflitos de gênero.

Pensando no papel do professor, Louro (2010), afirma que durante as aulas de Educação Física o professor tem a possibilidade de avaliar e analisar o comportamento dos alunos, podendo assim, exercitar a prática de um olhar incentivador sobre cada estudante, corrigindo sua conduta, sua postura, seu corpo, enfim, examinando e mediando suas ações constantemente.

Nas aulas de Educação Física podem ocorrer muitos conflitos oriundos das relações e manifestações de gênero, no entanto, o professor, deve estar preparado para atuar diante destes, fazendo com que meninos e meninas realizem as atividades propostas juntos, promovendo maior interação e motivação (CAMPOS, 2008). Parte-se do entendimento de que o professor enquanto mediador no processo ensino aprendizagem no espaço escolar deve, sobretudo, desenvolver mecanismos que operem contra essa segregação entre as categorias de gênero.

Nessa perspectiva, tendo em vista o quadro apresentado, o objetivo deste estudo foi analisar a atuação de professores frente às questões de gênero no cotidiano das aulas de Educação Física no ensino fundamental I e II em escolas da rede pública localizadas na cidade de Viçosa, MG.

\section{Metodologia}

Considerando o fenômeno a ser estudado, a trilha cientifica das ciências humanas e sociais se mostrou a mais indicada para nortear a averiguação dos objetivos estabelecidos. Este estudo se caracteriza como uma pesquisa de natureza qualitativa na qual, de acordo com Minayo (2012), trabalha-se com um universo de significados, motivos, aspirações, crenças, valores e atitudes. Isso corresponde a um espaço mais profícuo das relações, dos processos e dos fenômenos, que não podem ser reduzidos à operacionalização de variáveis.

O grupo amostral foi constituído de 4 professores licenciados em Educação Física (duas mulheres e dois homens), atuantes no ensino fundamental I e II em escolas da rede pública, localizadas na cidade de Viçosa, MG. Na definição dos participantes da pesquisa foram adotados os seguintes critérios de inclusão: ser professor licenciado em Educação Física atuante no ensino 
fundamental I ou II e, após serem informados sobre os objetivos da pesquisa, ter assinado as duas vias do Termo de Consentimento Livre e Esclarecido (TCLE). Foram considerados como critérios de exclusão os participantes que não atendiam aos critérios descritos ou não demonstraram interesse em participar da pesquisa.

Vale ressaltar que, em decorrência do número de observações sistemáticas proposta de aulas ministradas por diferentes docentes vinculados em escolas distintas, considerou-se um grupo amostral reduzido.

Os dados coletados foram obtidos a partir do emprego de duas técnicas: observação sistemática (SAMPIERI; COLLADO; LUCIO, 2013; RICHARDSON, 2007) e entrevista semiestrutura (BOGDAN; BIKLEN, 2010). A primeira consistiu no registro sistemático a partir da elaboração de categorias observáveis presentes no comportamento e condutas dos professores participantes da pesquisa. Foram consideradas as seguintes categorias: (1) Relação/interação entre alunos e alunas nas aulas; (2) Estruturação das aulas pelo(a) professor(a), considerando ou não a equidade de gênero; (3) Formas de lidar com as questões de gênero pelo professor e pela professora nas aulas.

Foram realizadas um total de 40 sessões de observação sistemática, sendo 10 sessões com cada um dos quatro professores atuantes em duas escolas da rede pública de ensino, localizadas na cidade de Viçosa, MG, no período de 27 de março a 16 de maio de 2018.

Concluído o período de observações, foram realizadas as entrevistas com os professores. Essas entrevistas aconteceram nas escolas mediante agendamento prévio com os participantes. O roteiro de entrevista foi elaborado tendo em vista os pressupostos teóricos presentes na literatura vigente que trata do fenômeno em questão.

$\mathrm{Na}$ análise dos dados resultantes das observações e entrevistas, foi empregada a análise de conteúdo que, de acordo com Bardin (2011), refere-se a um conjunto de técnicas de análise das comunicações visando obter, por procedimentos sistemáticos e objetivos de descrição do conteúdo das mensagens, indicadores quantitativos ou não que permitem a inferência de conhecimentos relativos às condições de produção/recepção (variáveis inferidas) destas mensagens. A autora organiza a análise de conteúdo a partir das fases: pré-análise, exploração do material e tratamento dos resultados, inferência e interpretação. Em consonância com essas fases, após transcrição e análise interpretativa dos dados, estes foram categorizados - por meio 
de agrupamentos em categorias constituídas por elementos comuns presentes nesses dados - e posteriormente quantificados a partir da frequência de ocorrência em que essas categorias se faziam presentes.

$\mathrm{Na}$ execução deste estudo, foram consideradas as diretrizes regulamentadas pela Resolução no 466/12 do CONEP, sendo o projeto de pesquisa aprovado pelo Comitê de Ética em Pesquisa com seres humanos da Universidade Federal de Viçosa, Parecer CEP №. 2.540.376, de 13 de março de 2018.

\section{Resultados e discussão}

A discussão desenvolveu-se através da triangulação entre os dados das observações das aulas e entrevistas com os professores participantes, a bibliografia utilizada que vinha ao encontro da temática abordada e, também, as posições assumidas pelos autores da investigação. Desta forma, foi possível uma compreensão e discussão aprofundada das categorias de análise que se encontram organizadas em duas partes: a primeira busca identificar a relação que se estabelece entre alunas e alunos nas aulas práticas; a segunda parte aborda formas de atuação e percepção das questões de gênero pelos professores nas aulas.

\section{Relação entre alunos e alunas nas aulas}

Indistintamente no ensino fundamental I e II foi observado a formação de grupos homogêneos - de alunas e de alunos - que se davam de maneira voluntária e naturalizada nos momentos em que as atividades aconteciam sem a intervenção dos professores no decorrer das aulas. No entanto, a depender do tipo de conteúdo selecionado e da atuação de alguns professores - que em raros momentos interviram no sentido de proporcionar a participação de toda a turma numa atividade proposta - foram registrados momentos de interação entre os grupos, indicando a existência de uma relação direta entre tais variáveis com a interação entre os alunos de ambos os sexos nas aulas. Nesses momentos, foi possível perceber que conteúdos como jogos e brincadeiras, em sua maioria, propiciaram maior interação entre os alunos de ambos os sexos. Já conteúdos como esportes coletivos, que mantém hegemonia nas aulas de

$$
\text { Periódico Horizontes - USF - Itatiba, SP - Brasil - e020014 }
$$


Educação Física, a segregação entre os gêneros se mostrou de forma mais evidente. Essa situação pode ser explicada por uma construção cultural da Educação Física e de determinadas modalidades esportivas como o futebol. Desde sua inserção nas escolas brasileiras, em 1851, tendo em vista as finalidades da Educação Física no âmbito escolar, a separação por sexo manteve-se até os anos de 1990 por respaldo legal nas escolas (DARIDO; RANGEL, 2005; UCHOGA; ALTMANN, 2016). A segregação entre práticas corporais e a sua especificação por sexo pautavam-se na ideia de nocividade às mulheres na sua função reprodutora, fragilidade, feminidade e funções domésticas. Como analisado por Dornelles e Fraga (2009), ainda que, no contexto atual, inexista legislações educacionais no sistema de ensino brasileiro que recomendam a separação de meninos e meninas nas aulas práticas, essa situação ainda se faz presente em muitas escolas no país. No entanto, mesmo que tais construções de gênero que colocam os meninos como mais habilidosos não sejam verdades absolutas, as meninas esquivam-se de certos jogos e esportes por não se sentirem capazes no espaço das aulas de Educação Física (UCHOGA; ALTMANN, 2016). A história mostra que a Educação Física traz, em suas práticas, heranças da exclusão da mulher no desporto devido principalmente a sua condição biológica. Wenetz e Stigger (2006) relatam que o esporte funciona como uma legitimação da masculinidade e que não há espaço para as meninas brincarem por dois motivos: serem meninas e menos habilidosas.

Nessa perspectiva, mostrou-se de forma equivocadamente naturalizada nas turmas observadas que a quadra é por direito dos meninos e na maioria das vezes, por exemplo, eles detiam a posse da bola e as meninas precisavam manifestar a vontade de jogar a modalidade futsal para que assim, houvesse intervenção dos professores, no sentido de garantir a participação delas no jogo com os meninos. Essa situação remete ao estudo realizado por Mattos e Jaeger (2015), em que afirma que no ambiente escolar não há uma regra ou norma que estabelece que a quadra é dos meninos, mas eles se apropriam deste espaço como se fosse um local masculino, o legitimando como local masculino. Foi observado ainda, que, não raras às vezes, os momentos de interação entre alunos de ambos os sexos eram marcados por implicâncias, resistências, discussões e, em alguns casos, pela indiferença por parte das meninas com relação aos meninos. De acordo com alguns estudiosos (LOURO, 2010; MATTOS; JAEGER, 2015) as crianças preferem brincar com pares que the são similares, tanto psicologicamente, 
quanto fisicamente, e que essas diferenças são mais evidentes entre meninos e meninas, causando afastamento e/ou conflitos nas aulas. Essa situação resulta, sobretudo, de uma pedagogia que educa de modo diferenciado os corpos dos meninos e os corpos das meninas. Nessa perspectiva, Uchoga e Altmann (2016) complementam a ideia ao afirmarem que as expectativas, bem como reforço de comportamentos e atitudes distintas entre meninos e meninas, são direcionadas aos corpos de ambos desde cedo, seja na família, entre brincadeiras com seus pares, ou na escola.

\section{Formas de atuação e percepção das questões de gênero pelos professores nas aulas}

Como já mencionado, a maneira como o professor conduz e/ou estrutura suas aulas, levando ou não em consideração os princípios de uma didática de ensino crítica repercutem diretamente no ambiente de aprendizagem. A partir das observações realizadas, verificou-se que a seleção dos conteúdos trabalhados pelos professores influencia diretamente nas relações de gênero nas aulas de Educação Física. Dentre os aspectos que podem explicar essa inter-relação se fazem presentes fatores como a Educação Física ter como objeto de estudo o movimento humano e ainda pelas relações de poder historicamente existentes em suas práticas corporais de movimento e, que mediatizam hegemonias na ambiência escolar como tem sido o caso do esporte, mais especificamente modalidades coletivas como o futsal e voleibol (LEITE; FEIJÓ; CHIÉS, 2016).

Em todas as fases do ensino fundamental foi observado que, na maioria das vezes, os professores elaboravam as atividades, mas os próprios alunos decidiam como os grupos iriam ser divididos, tendendo assim a formação de duplas ou pequenos grupos homogêneos e às vezes a competição de meninas contra meninos. Em alguns casos, os professores oportunizavam atividades variadas em que os alunos podiam escolher de acordo com a afinidade. Nesse sentido, meninas acabavam escolhendo uma atividade e meninos outra. De uma maneira geral, os professores buscavam encorajar a participação das turmas nas atividades propostas nas aulas. No entanto, nem sempre o mesmo acontecia quanto se tratava no tratamento e participação equânime entre os gêneros nas aulas. Comumente, nas atividades em que os professores organizavam as turmas em grupos heterogêneos quanto ao sexo, buscava-se, sobretudo, o 
equilíbrio entre as equipes, e não necessariamente a interação e a igualdade entre os alunos e alunas nos espaços em que aconteciam as aulas. Geralmente as meninas participam das aulas de forma mais passiva por não terem a mesma oportunidade de vivenciar, de forma mais intensa, as diversas práticas como a maioria dos meninos e, assim, naturaliza-se a ideia de estarem em segundo plano na aula, culminando na recusa em participar das aulas (WENETZ; STIGGER, 2006).

De acordo com Corsino e Auad, (2012), deve-se estabelecer nas aulas de Educação Física a perspectiva coeducativa em que a igualdade e a valorização entre os gêneros sejam privilegiadas e discutidas, assim como, o debate sobre o que é conhecido como pertencente ao masculino e ao feminino e o que significa ficar preso a este pertencer.

Quanto as formas de lidar com as questões de gênero pelo professor nas aulas, identificou-se que nos anos iniciais, os professores reforçavam a segregação entre alunas e alunos, por exemplo, com a formação de filas para meninas de um lado e meninos para o outro, algo que é corrente nas escolas em nome de uma certa organização. Já quando havia alguma rivalidade entre eles, os professores resolviam com orientações do tipo: "ela é menina, cuidado com ela"; "pode ser menina e menino, qual problema de vocês jogarem juntos?", mas não problematizavam aspectos relacionados às questões de gênero nas aulas observadas.

Verificou-se ainda que o fato de se tratar de um professor ou de uma professora à frente na condução das aulas não interferiu nas decisões e ações relacionadas às questões de gênero nas aulas práticas de Educação Física. Esse fato mostrou-se coerente com os posicionamentos relatados pelos professores e professoras acerca das questões de gênero nas entrevistas. Em suma, as questões de gênero eram silenciadas nas aulas. Situação que coaduna com o estudo realizado por Corsino e Auad (2012) que identificaram que as relações de gênero nas aulas de Educação Física não são discutidas, o que contribui para a construção de identidades conformistas em relação às segregação e inequidade de gênero no espaço escolar.

\section{Conclusão}

Diante das constatações obtidas, nesta investigação, e considerando suas limitações metodológicas, é possível afirmar que, ainda que se tenha considerado as aulas de Educação Física na ambiência do ensino fundamental I e II para analisar aspectos relacionados as questões 
de gênero, estudos sobre essa temática tem mostrado que a referida problemática tem-se feito presente indistintamente em outros níveis que compõem a educação básica nas aulas de Educação Física e que, por sua vez, suscita antigas discussões, não somente nos cursos de formação inicial de professores quanto na ambiência das escolas de educação básica do país.

No que se refere a percepção dos professores quanto as questões de gênero nas aulas, evidenciou-se um desconhecimento atribuído pelos mesmos, indistintamente de se tratar de professor ou professora às fragilidades da formação inicial, bem como da omissão da escola em abordar o tema em seu cotidiano. Como decorrência, foi identificado no decorrer das aulas, uma espécie de silenciamento das questões relacionadas a gênero que se efetivaram na ausência de equidade da participação de alunos e alunas nas atividades propostas pelos professores nas aulas. Tal silenciamento pode estar relacionado ao desconhecimento por parte dos docentes acerca dos aspectos que circunscrevem as relações de gênero, bem como o referido fenômeno pode e deve ser abordado no cotidiano das aulas de Educação Física.

Merece destaque o fato que, nos raros momentos em que alguns professores intervinham como moderadores durante as atividades propostas nas aulas, praticamente não foram observados a formação de grupos distintos de meninos e meninas, resultando, em sua maioria, participação equânime entre ambos os sexos. Com isso, percebia-se uma diminuição daquela parcela de alunos que geralmente se recusa em participar das aulas de Educação Física. Essa situação desmistifica no imaginário que prevalece nos espaços da escola de que as meninas não têm interesse em participar das atividades propostas nas aulas de Educação Física.

Nessa direção, reforçar ou mesmo ignorar as questões relacionadas ao gênero nas aulas de Educação Física, que pela sua própria especificidade evidencia o corpo em movimento potencializa, sobretudo a desigualdade de participação de alunas e alunos nos diversos conteúdos tematizados pela Cultura Corporal de Movimento. Sobretudo, como asseveram Lim e Dixon (2018), as práticas corporais de movimento de uma maneira geral, com ênfase no esporte tem sido considerada profícuas ferramentas catalisadoras de mudanças atitudinais no que concerne ao gênero feminino, possibilitando elementos importantes, os quais contribuem efetivamente para o empoderamento da mulher como a melhoria da autoestima, da confiança, da autossuperação e da autonomia, tais elementos, indubitavelmente, tendem a contribuir para uma possível mudança de conceito em relação à presença dos gêneros, feminino e masculino, 
em equipes esportivas.

Indubitavelmente, o tratamento igualitário entre homem e mulher no campo de Educação Física - dada a sua construção cultural que culminou a base em que ainda se encontra alicerçada - configura-se tarefa árdua. Para tanto, dentre os caminhos para que o processo que poderá trazer mudanças se efetive, faz-se necessário refletir sobre o corpo, que por muito tempo foi visto pelos professores da área como apenas um corpo orgânico, fato este que acabou legitimando determinada cultura no cotidiano das aulas de Educação Física, pois, a forma como a professora e o professor entende o corpo acaba refletindo na forma como as aulas são desenvolvidas. Nesse cenário em que se tem a Educação Física como foco para as questões de gênero, é possível vislumbrar evolução dos elementos que permeiam as discussões e propostas de trabalho, que vem sendo efetivadas por professores e professoras, de práticas corporais de movimento na ambiência das muitas escolas de educação básica e, ainda, se encontram fora do radar dos pesquisadores que se dedicam à referida temática em questão.

Nessa direção, faz-se necessário que o professor crie espaços em suas aulas para a desconstrução desses padrões, a partir do questionamento e reflexão por parte dos alunos por meio de suas próprias experiências corporais. Assim, as experiências corporais não ficariam enclausuradas em um padrão modelador do que a sociedade estipula como ideal nas questões de comportamento e habilidades para o feminino e para o masculino.

\section{Agradecimentos}

Fundação de Amparo à Pesquisa do Estado de Minas Gerais - FAPEMIG.

\section{Referências}

BARDIN, L. Análise de conteúdo. 1a reimpressão da 1a ed. Inserir edição. Lisboa: Edições 70, 2011.

BOGDAN, R.; BIKLEN, S. Investigação Qualitativa em Educação: Uma Introdução à Teoria e aos Métodos. 6a ed. Porto: Porto Editora. 2010. 
CAMPOS, A. F. et al. A questão de gênero nas aulas de Educação Física, Revista Brasileira de Educação Física, Esporte, Lazer e Dança, Ubá, MG, v.3, n. 3, p. 79-88, set. 2008.

CORSINO, L. N.; AUAD, D. O professor diante das relações de gênero na Educação Física Escolar. 1a ed. São Paulo: Cortez, v.7, 2012.

CRUZ, M. M. S.; PALMEIRA, F. C.C. Construção de identidade de gênero na Educação Física Escolar. Motriz, Rio Claro, v.15, n.1, p.116-131, jan./mar. 2009.

DARIDO, S. C.; RANGEL, I. C. A. Educação Física na Escola: implicações para a prática pedagógica.1a ed. Rio de Janeiro: Guanabara Koogan, 2005.

DORNELLES, P. G.; FRAGA, A. B. Aula mista versus aula separada? Uma questão de gênero recorrente na educação física escola. Revista Brasileira de Docência, Ensino e Pesquisa em Educação Física, Paraná, v.1, p.141-156, ago. 2009.

KUNZ, E. Transformação didático-pedagógica do esporte. 5aed. ljuí: Ed. Unijuí, 2003.

LEITE, L. G.; FEIJÓ, J. P.; CHIÉS, P. V. Qual o gênero do brincar? Aprendendo a ser "menino"... Aprendendo a ser "menina". Motrivivência, Florianópolis, v.28, n.47, p.210-225, maio/2016.

LIM, S. Y.; DIXON, M. A. A conceptual framework of sport participation and women's empowerment. Managing Sport and Leisure, Abingdon, v. 1, n. 1, p. 1-15, jul. 2018.

LOURO, G. L. Gênero, sexualidade e educação: uma perspectiva pós-estruturalista. 11 Ed. Petrópolis, RJ: Vozes, 2010.

MATTOS, M. Z.; JAEGER, A. A. Bullying e as relações de gênero presentes na escola, Movimento, Porto Alegre, v. 21, n. 2, p. 349-361, abr./jun. de 2015.

MINAYO M. C. S. (org.) Pesquisa Social: teoria, método e criatividade. 32a. ed. Petrópolis: Vozes; 2012.

MIRANDA, A. P. M.; MAIA, B. Olhares, xingamentos e agressões físicas: A presença e a (in)visibilidade de conflitos referentes às relações de gênero em escolas públicas do Rio de Janeiro. Horizontes Antropológicos, Porto Alegre, ano 23, n.49, p.177-202, set./dez. 2017.

PEREIRA, S. A. M.; MOURÃO, L. Identificações de gênero: jogando e brincando em universos divididos, Motriz, Rio Claro, v.11, n.3, p.205-210, set./dez. 2005.

RICHARDSON, R. J. Pesquisa social: métodos e técnicas. 3a ed. São Paulo: Atlas, 2007.

SAMPIERI, R. H.; COLLADO, C. F.; LUCIO, M. D. P. B. Metodologia de pesquisa, 5a ed. São Paulo: Artmed, 2013. 
SILVA, P.; GOMES, P. B.; QUEIRÓS, P. Educação Física, Desporto e Género: o caminho percorrido na Faculdade de Desporto da Universidade do Porto (Portugal). Movimento, Porto Alegre, v.12, n. 01, p. 31-58, jan./abr. 2006.

UCHOGA, L. A. R.; ALTMANN, H. Educação Física escolar e relações de gênero: diferentes modos de participar e ariscar-se nos conteúdos das aulas. Revista Brasileira de Ciências do Esporte, v.38, n. 02, p. 163-170, 2016.

WENETZ, I.; STIGGER, M. P.; A Construção do Gênero no Espaço Escolar. Revista Movimento. Porto Alegre, v.12, n. 01, p. 59-80, janeiro/abril de 2006.

Recebido em julho de 2018.

Aprovado em janeiro de 2020. 